\title{
Update on alternative therapies for vulvovaginal atrophy
}

\author{
This article was published in the following Dove Press journal: \\ Patient Preference and Adherence \\ 27 October 201I \\ Number of times this article has been viewed
}

\author{
Janet A Chollet ${ }^{1,2}$ \\ 'Beth Israel Deaconess Medical \\ Center, Boston, ${ }^{2}$ Pear Tree \\ Pharmaceuticals, Waltham, MA, USA
}

Correspondence: Janet A Chollet Beth Israel Deaconess Medical Center, 330 Brookline Avenue, Boston, MA 022I, USA

Tel +l 6172765207

Fax + I61752|6795

Email jchollet@bidmc.harvard.edu

\begin{abstract}
Although systemic absorption of estrogen with local treatment for vulvovaginal atrophy (VVA) is most likely to be negligible, it is unknown whether this minimal absorption will affect outcomes in women with breast cancer. Use of adjuvant therapy with aromatase inhibitors for breast cancer is associated with high incidence of VVA symptoms. Because of the impact of moderate to severe VVA symptoms on the quality of life in breast cancer survivors, there has been an intense search for alternative therapies. Further, the publicity that followed the publication of data from the Women's Health Initiative Study has led to the suggestion by the medical community to use the lowest dose therapy possible for minimal time duration in order to avoid risks. This article will highlight the progress in alternative therapies for VVA.
\end{abstract}

Keywords: vulvovaginal atrophy, hormone therapy, alternative therapy

\section{Introduction}

In general, only $20 \%-25 \%$ of symptomatic women seek medical help for the treatment of vulvovaginal atrophy (VVA), despite the availability of US Food and Drug Administration-approved treatment. The fear of breast cancer associated with the prescription of hormone therapy (HT) is the main reason for lack of acceptance of HT by most women. Even clinicians are asking whether it is time to stop prescribing even short courses of such treatment in view of the recent publication linking menopausal HT with breast cancer. ${ }^{1}$ The American College of Obstetricians and Gynecologists opined that "HT use should be limited to the treatment of menopausal symptoms at the lowest effective dosage over the shortest duration possible and continued use should be reevaluated on a periodic basis." 2

On average, women have safety concerns about the prescription of HT even at the lowest effective dosage over the shortest duration possible. The results of a survey that evaluated the prevalence and impact of VVA symptoms and perceptions about safety of HT among women were reported at the North American Menopause Society (NAMS) annual meeting in 2008; of the 2290 respondents, $45 \%$ of women said that they experience or had experienced symptoms of VVA. ${ }^{3}$ The most common symptoms were vaginal dryness, pain, irritation, and itching. HT-related safety concerns were the main reason for discontinuance of HT or it never having being used among respondents. For those women using HT, a third expressed concerns about its long-term safety and would prefer estrogen-free products to treat their condition. Of the women who had never used HT, 26\% assumed their symptoms would go away over time.

Safety appears to be of paramount importance to this patient population, which is as important or more important than efficacy. The majority of women simply will not 
use HT. Also, the VVA market is substantially underserved. Less than a third of the potential patients are being treated, and a large number of those being treated could likely be convinced to use a product that has been demonstrated to be safer than HT. Even though the market is underserved, almost US\$2 billion of HT is still sold annually in the USA alone. ${ }^{4}$ Vaginal HT, used exclusively for VVA, sold about US\$500 million in 2008. Presently, local estrogen therapy, given as estrogen creams, vaginal estradiol tablets, and estrogen rings, is the treatment of choice for women with vaginal atrophy who do not have other menopausal symptoms, according to the 2010 NAMS guidelines. ${ }^{5}$

Generally, due to concerns about adverse effects of exogenous estrogens, there is growing interest in alternative therapies for VVA. This interest has been the focus in menopausal women with breast cancer being treated with aromatase inhibitors, who can experience a worsening of their VVA symptoms due to profound estradiol suppression. ${ }^{6}$ As more women living with breast cancer are being treated with aromatase inhibitor therapy, and these drugs move into a different adjuvant setting, such side effects are an increasing issue for women.

Third-generation aromatase inhibitors, which suppress circulating estrogen by more than $95 \%-97 \%$, are more effective in reducing the risk of breast cancer recurrence than first-generation aromatase inhibitors, which reduce circulating estrogens by $90 \%$. As local estrogens increase circulating estrogens, they may mitigate the effectiveness of the adjuvant therapy. Moreover, many women will not take estrogen therapy, including local estrogen therapy, because of real or perceived risks of the treatment. Thus, many women undergoing breast cancer treatment and related adjuvant therapy suffer diminished quality of life as they currently have no safe and effective treatment for their condition. Coupled with the pertinent recommendations from the US Food and Drug Administration and NAMS Position Statement, there is a clear medical need for an effective "estrogen-free" alternative to treat VVA.

\section{Alternative treatments}

Currently, the 600,000 US women taking aromatase inhibitors report symptoms of VVA at about twice the rate of the general population. A population-based, crosssectional study on menopausal breast cancer patients on adjuvant endocrine treatment demonstrated that $57.6 \%$ of aromatase inhibitor-treated breast cancer patients rated vaginal atrophy symptoms as moderate/severe. Aromatase inhibitor-treated patients more often had an atrophic cytohormonal evaluation $(P<0.05)$ and significantly higher vaginal $\mathrm{pH}(P<0.05)$ than all control subjects. ${ }^{7}$ Overall, the authors agreed that because use of estradiol for relief may be problematic in these patients, research should focus on treatment options other than estradiol to alleviate their symptoms of VVA. To date, alternative therapies have included selective estrogen receptor modulators (SERMs) and selective tissue estrogenic activity regulators (STEARs). There are several products currently in clinical development (Table 1).

The most advanced SERM product candidate is ospemifene $\left(\right.$ Ophena $^{\mathrm{TM}}$ ), a novel orally delivered SERM to treat VVA developed by QuatRx ${ }^{\mathrm{TM}}$ Pharmaceuticals Company (Ann Arbor, MI). Ospemifene completed the second pivotal Phase III clinical trial and, according to QuatRx, achieved all endpoints. The results $(\mathrm{N}=826)$ showed that ospemifene was statistically significantly $(P<0.001)$ superior to placebo in maturation index, vaginal $\mathrm{pH}$, and "most bothersome" symptom (vaginal dryness or dyspareunia) with a $60 \mathrm{mg}$ dose. ${ }^{8}$ Concerning dyspareunia, a daily $30 \mathrm{mg}$ dose did not have a statistically significant effect compared with placebo, while a $60 \mathrm{mg}$ dose reached significance. Women with an intact uterus were enrolled into an extension safety study where the treatment blind was maintained for 12 months. In this study, 83\% taking $60 \mathrm{mg}$ daily completed the study compared with $69 \%$ on placebo. No trends were apparent in severe treatmentemergent adverse events and there were no cases of venous thromboembolism, endometrial hyperplasia, or carcinoma. ${ }^{9}$ A new drug application for ospemifene for the treatment of VVA utilizing clinical trials that were conducted by QuatRx will be filed.

The most advanced STEAR product in clinical development by Pfizer, Inc (New York, NY) includes a combination of oral

Table I Alternative therapies for vulvovaginal atrophy in clinical development

\begin{tabular}{lllll}
\hline Drug name & Drug category & Route of administration & Pharmaceutical company & Clinical phase \\
\hline Ospemifene & SERM & Oral & QuatRx ${ }^{\text {TM }}$ Pharmaceuticals Co, Ann Arbor, MI & NDA \\
BZA/CE & STEAR & Oral & Pfizer, Inc, New York, NY & Phase III \\
Prasterone ${ }^{\circledR}$ & Androgen derivative & Vaginal & EndoCeutics, Inc, Quebec, Canada & Phase III \\
Seale $^{\circledR}$ & SERM & Vaginal & Bionovo, Inc, Emeryville, CA & Phase I-II \\
\hline
\end{tabular}

Abbreviations: BZA/CE, bazedoxifene/conjugated estrogens; NDA, new drug application; SERM, selective estrogen receptor modulator; STEAR, selective tissue estrogenic activity regulator. 
bazedoxifene (BZA) and conjugated estrogens (CE). Results of the 12-week $(\mathrm{N}=652)$ Selective Estrogen Menopause and Response to Therapy 3 trial demonstrated improvement in the percent of superficial cells $(P<0.01)$ and vaginal $\mathrm{pH}(P<0.05)$ at two BZA/CE doses $(20 \mathrm{mg} / 0.45 \mathrm{mg}, 20 \mathrm{mg} / 0.625 \mathrm{mg})$ compared with placebo and BZA monotherapy. ${ }^{10}$ The largest $(\mathrm{N}=3397)$ and longest (2 years) study of BZA/CE reported significantly improved VVA symptoms and demonstrated endometrial hyperplasia rates similar to that with placebo. ${ }^{11}$ Longer-term safety with regard to cardiovascular and breast effects have not been established. Overall, the authors concluded that the favorable efficacy and safety profiles of BZA/ CE support the use of a STEAR product containing BZA/CE as a new therapy for VVA in menopausal women.

Another product candidate in clinical development is Prasterone $^{\circledR}$ (EndoCeutics, Inc, Quebec, Canada). The intravaginal formulation containing dehydroepiandrosterone (DHEA) has completed a Phase III trial $(\mathrm{N}=216)$. After 12 weeks, a significant increase in superficial cells $(P<0.0001)$ and a decrease in vaginal $\mathrm{pH}(P<0.0001)$ were found. Comparable effects were observed at $0.25 \%$ (3.25 mg DHEA) and $1.0 \%$ (13 mg DHEA) doses. ${ }^{12}$ In another clinical trial $(\mathrm{N}=114)$, the effects of Prasterone on the severity of dyspareunia on those who had identified it as their most bothersome symptom was studied. After 12 weeks of treatment, the severity score of pain during sexual activity decreased significantly even at the lowest dose $(0.25 \%, 3.25 \mathrm{mg}$ DHEA) when compared with the placebo group $(P<0.0001) .{ }^{13} \mathrm{~A}$ second Phase III clinical trial is underway $(\mathrm{N}=345)$ using $0.25 \%$ (3.25 mg DHEA) and $0.5 \%$ (6.5 mg DHEA) compared with placebo over 12 weeks. ${ }^{14}$ Of concern, Prasterone is a precursor to estrogen and therefore must be converted to estrogen to be effective. Further safety studies are needed to determine if this is just another way of delivering exogenous estrogens.

Seala $^{\circledR}$ (Bionovo, Inc, Emeryville, CA) is another potential product candidate. Seala appears to be a Chinese herbal extract selective to estrogen receptor beta and is in early development. A Phase II clinical trial $(\mathrm{N}=217)$ using an oral formulation of the herbal extract decreased the frequency of hot flashes compared with placebo after 12 weeks of treatment $(P=0.05) .{ }^{15}$ A randomized, blinded, placebocontrolled, dose-escalating clinical trial in four cohorts of 10 menopausal women (total $\mathrm{N}=40$ ) of a vaginal formulation (VG-101) is expected to start soon (June 2012). ${ }^{16}$ Seala's regulatory pathway is unclear.

A study $(\mathrm{N}=90)$ currently underway will measure the effects of the lowest doses (1/10 of the current therapeutic doses $)$ of estradiol cream $(10 \mathrm{mcg})$ or estriol cream $(10 \mathrm{mcg})$ in the treatment of VVA. ${ }^{17} \mathrm{~A}$ randomized controlled trial with three arms, estradiol, estriol, and placebo, will be conducted. The intervention will last for 12 weeks. Outcomes will be measured, primarily, by the use of patient questionnaires and, secondarily, clinical examination scores. Safety will be evaluated with serum estrogen concentrations. All measures will be collected at baseline and at the termination of the study. Hormone concentrations will be collected, additionally, at week 2 . This trial will answer important questions regarding the impact of very low doses of locally applied estrogens on symptoms of VVA. It will also give information about whether very low doses of estrogen creams, locally applied, result in systemic absorption.

\section{Conclusion}

Overall, it has been estimated that approximately 50\% of menopausal women experience varying degrees of VVA. With the decline of the use of systemic HT, there is a greater need for effective, safe, and convenient local therapies to ameliorate symptoms of VVA. According to the latest evidence-based position statement of NAMS, there is a growing body of evidence that HT, regardless of route of administration and timing of delivery, has certain benefits and risks. Vaginal estrogen therapy is safe and well tolerated in menopausal women, though these conclusions are based on experience in small trials, largely of short duration. Further, in the absence of more rigorous studies suggesting otherwise, vaginal estrogens are not indicated for women receiving adjuvant aromatase inhibitor therapy for breast cancer. Thus, the safety of HT use in breast cancer survivors has not been fully established and there remains concern that it may be associated with an increased risk for breast cancer recurrence. Further research remains essential. ${ }^{5}$ The challenge is to find an alternative therapy that will maximize all the benefits of HT while minimizing all the risks. Therein lies the challenge for many years to come.

\section{Disclosure}

The author is Director and Founder of Pear Tree Pharmaceuticals, Waltham, MA. No other conflicts of interest in relation to this paper are declared.

\section{References}

1. Chlebowski RT, Anderson GL, Gass M, et al. Estrogen plus progestin and breast cancer incidence and mortality in postmenopausal women. JAMA. 2010;304(15):1684-1692.

2. American College of Obstetricians and Gynecologists Committee on Gynecologic Practice. ACOG Committee Opinion No. 420 November 2008: hormone therapy and heart disease. Obstet Gynecol. 2008;112(5):1189-1192. 
3. Santoro N, Komi J. Prevalence and impact of vaginal symptoms among postmenopausal women. $J$ Sex Med. 2009;6(8):2133-2142.

4. IMS. 2008 US sales and prescription information. [Data from IMS Health's DDA Service.] Danbury, CT: IMS Health; 2009. Available from: http://www.imshealth.com.

5. North American Menopause Society. Estrogen and progestogen use in postmenopausal women: 2010 position statement of the North American Menopause Society. Menopause. 2010;17(2):242-255.

6. Morales L, Neven P, Timmerman D. Acute effects of Tamoxifen and third-generation aromatase inhibitors on menopausal symptoms of breast cancer patients. Anticancer Drugs. 2004;15(8):753-760.

7. Baumgart J, Nilsson K, Stavreus-Evers A, et al. Urogenital disorders in women with adjuvant endocrine therapy after early breast cancer. Am J Obstet Gynecol. 2011;204(1):26. e1-e7.

8. Bachmann GA, Komi JO; Ospemifene Study Group. Ospemifene effectively treats vulvovaginal atrophy in postmenopausal women: results from a pivotal phase 3 study. Menopause. 2010;17(3):480-486.

9. QuatRx ${ }^{\mathrm{TM}}$. Ophena ${ }^{\mathrm{TM}}$ (ospemifene) [web page on the Internet]. Ann Arbor, MI: QuatRx; nd. Available from: http://www.quatrx.com/clinical/ospem. htm. Accessed September 17, 2010.

10. Kagan R, Williams RS, Pan K, Mirkin S, Pickar JH. A randomized, placebo- and active-controlled trial of bazedoxifene/conjugated estrogens for treatment of moderate to severe vulvar/vaginal atrophy in postmenopausal women. Menopause. 2010;17(2):281-289.

11. Levine JP. Treating menopausal symptoms with tissue-selective estrogen complex. Gend Med. 2011;8(2):57-68.

12. Labrie F, Archer D, Bouchard C, et al. Intravaginal dehydroepiandrosterone (Prasterone), a physiological and healthy efficient treatment of vaginal atrophy. Menopause. 2009;16(5):907-922.
13. Labrie F, Archer D, Bouchard C, et al. Intravaginal dehydroepiandrosterone (Prasterone), a highly effective efficient treatment of dyspareunia. Climacteric. 2011;14(2):282-288.

14. EndoCeutics Inc. Dehydroepiandrodrosterone (DHEA) against vaginal atrophy. In: ClinicalTrials.gov [website on the Internet]. Bethseda, MD: US National Library of Medicine; 2011 [updated July 29, 2011]. Available from: http://clinicaltrials.gov/ct2/show/NCT01358760?term=NCT01358 760\&rank=1. NLM identifier: NCT01358760. Accessed September 14, 2011.

15. Grady D, Sawaya GF, Johnson KC, et al. MF101, a selective estrogen receptor beta modulator for the treatment of menopausal hot flushes: a phase II clinical trial. Menopause. 2009;16(3):458-465.

16. Bionovo. VG101 Phase I/II to treat vulvar and vaginal atrophy in postmenopausal women. In: ClinicalTrials.gov [website on the Internet]. Bethseda, MD: US National Library of Medicine; 2007 [updated June 6, 2011]. Available from: http://clinicaltrials.gov/ct2/show/ NCT00453089?term $=$ NCT00453089\&rank=1. NLM identifier: NCT00453089. Accessed September 14, 2011.

17. Mayo Clinic. A trial to evaluate the efficacy of low dose vaginal estrogens in the treatment of atrophic vaginitis. In: ClinicalTrials.gov [website on the Internet]. Bethseda, MD: US National Library of Medicine; 2008 [updated May 2, 2011]. Available from: http://clinicaltrials.gov/ct2/ show/NCT00816556?term=NCT00816556\&rank=1. NLM identifier: NCT00816556. Accessed September 14, 2011.
Patient Preference and Adherence

\section{Publish your work in this journal}

Patient Preference and Adherence is an international, peer-reviewed, open access journal focusing on the growing importance of patient preference and adherence throughout the therapeutic continuum. Patient satisfaction, acceptability, quality of life, compliance, persistence and their role in developing new therapeutic modalities and compounds to

\section{Dovepress}

optimize clinical outcomes for existing disease states are major areas of interest. This journal has been accepted for indexing on PubMed Central. The manuscript management system is completely online and includes a very quick and fair peer-review system. Visit http://www.dovepress.com/ testimonials.php to read real quotes from published authors. 